Pooled estimates of prevalence in other populations were: pregnant women $1.2 \%$ (95\% CI 0.4 to $1.9 \%, \mathrm{I}^{2} 85.1 \%, 4$ studies); men who have sex (MSM) in the general population 2.3\% $(95 \%$ CI 1.6 to $3.1, \mathrm{I}^{2} 0 \%, 3$ studies); and clinic-based samples of MSM 5.2\% (95\% CI 4.2\% to $6.1 \%, \mathrm{I}^{2} 0 \%, 2$ studies). In female sex workers in low income countries, prevalence estimates ranged from 13.2 to $26.3 \%$ (4 studies).

Discussion Prevalence rates of M. genitalium in the overall general population, population-based samples of MSM and pregnant women in high income countries are low. Estimates of prevalence are higher in MSM in clinic-based samples and in female sex workers in low income countries.

\section{P130 NATURAL HISTORY OF MYCOPLASMA GENITALIUM: INCIDENCE, PERSISTENCE, TRANSMISSIBILITY AND PROGRESSION TO PELVIC INFLAMMATORY DISEASE: SYSTEMATIC REVIEW AND META-ANALYSIS}

${ }^{1}$ Manuel Cina, 'Lukas Baumann, ${ }^{1}$ Myrofora Goutaki, ${ }^{1}$ Florian Halbeisen, ${ }^{2}$ Hammad Ali, ${ }^{1}$ Fabio Giudici, 'Dianne Egli-Gany, ${ }^{1}$ Nicola Low*. ' University of Bern, Bern, Switzerland; ${ }^{2}$ University of New South Wales, Sydney, Australia

10.1136/sextrans-2016-052718.184

Background Mycoplasma genitalium causes urethritis in men and cervicitis in women but characteristics of the infection have not been systematically reviewed.

Objectives To determine the incidence, persistence and transmissibility of M. genitalium and its role in pelvic inflammatory disease (PID).

Methods We searched Medline, EMBASE, LILACS, IndMed and African Index Medicus. Two investigators selected studies and extracted data independently. We examined the findings in forest plots and assessed heterogeneity using the $\mathrm{I}^{2}$ statistic. We conducted meta-analysis if appropriate.

Results Of 4355 abstracts we included 6, 5, 9 and 3 studies about incidence, persistence, transmissibility and PID respectively. Study designs were heterogeneous. In high income countries the pooled incidence was 1.1 per 100 person-years $(95 \%$ CI, 0.5 to $1.7, \mathrm{I}^{2} 28.3 \%, 3$ studies). The proportion of infected people who cleared infection were 50\% after 2.5 months and $<90 \%$ after 8 months but in one study $25.9 \%$ had persistent infection after a median of 16 months. In studies of people with M. genitalium the proportion of sexual partners also infected was $55 \%$ (95\% CI 40 to $\left.70 \%, \mathrm{I}^{2} 61.5 \%\right)$ and in cross-sectional studies 1 to $22 \%$ of couples were concordantly infected. Two cohort studies found PID more commonly in women with $M$. genitalium than in uninfected women (risk ratios 2.4, 95\% CI 0.7 to 7.5 and $1.6,95 \%$ CI 0.8 to 3.1 ).

Discussion Further studies of the natural history of M. genitalium are warranted. These estimates can be used in mathematical modelling studies of M. genitalium dynamics.

\section{P131 LESSONS LEARNT FROM PATIENT PUBLIC INVOLVEMENT}

Sarah Cochrane*, Michael Clarke, Jackie Haskins, Lucinda Farmer. Bristol Sexual Health Clinic, Bristol, UK

10.1136/sextrans-2016-052718.185
Background/introduction NHS England are clear that patients and carers should supported in their involvement to help shape NHS services. Patient public involvement (PPI) groups to determine patients' views can be used to plan and improve services.

Aim(s)/objectives To hold a patient focus group discussing expectations of an integrated GUM clinic and explore patient views regarding engagement with our service.

Methods A survey given to all patients assessed views on PPI. Interested patients were requested to complete contact details. 12 mixed sex patients confirmed to attend a 90 minute session at a local venue, facilitated by an independent lead. Topics were decided in advance. Responses were documented by clinicians.

Results 306 completed the survey: 89\% agreed patient involvement is important. 65 left contact details. 5/12 confirmed participants attended the session; all were male. All stated they would participate in future PPI sessions, and would be agreeable if held within our clinic.

Discussion/conclusion The survey demonstrated that patients agree public involvement is beneficial. However, only a fifth agreed to be contacted for this project. The focus group provided valuable development suggestions including increasing bookable appointments and introducing online triage. Acceptability of holding groups within our clinic enables a financial saving compared to external venues. Adequate participant numbers remains a challenge, with further sessions achieving a similar 50\% attendance. Suggestions include reducing time between survey and date of focus group. Increasing invited numbers would allow for high drop-out rates. Trialling targeted focus groups e.g. single sex or telephone interviews may improve patient acceptability.

\section{P132 REVIEW OF SMOKING, ALCOHOL AND DRUG USE WITHIN AN INNER-CITY INTEGRATED GUM SERVICE}

Sarah Cochrane*, Johnny Boylan, Helen Wheeler, Paddy Horner. Bristol Sexual Health Clinic, Bristol, UK

\subsection{6/sextrans-2016-052718.186}

Background/introduction Evidence suggests alcohol and drug use correspond to poorer sexual health outcomes. NICE recommend routine screening for alcohol use disorders, with adults and young people regularly attending GUM services identified as a high risk group. Assessment for drug and alcohol misuse enables health promotion through brief intervention.

Aim(s)/objectives To assess the prevalence of cigarette, alcohol and drug use within our GUM clinic population.

Methods Patients were requested to complete a questionnaire as part of the clinic triage form, including data on smoking status, alcohol use using AUDIT-C and recreational drug use. Cases were randomly selected for retrospective review over two weeklong periods in June-July 2015.

Results 493 patients were reviewed: 261 (52.9\%) female vs 232 $(47.1 \%)$ male. Ages ranged from 14-79 (median = 28). $27.9 \%$ were current smokers ( $\mathrm{F}=26.8 \%, \mathrm{M}=29.2 \%) .391$ (79.3\%) patients completed questions to allow adequate assessment of their alcohol use. $220(56.3 \%)$ scored $\geq 5$ using the AUDIT-C screening tool, indicating need for further discussion. 317/409 $(77.5 \%)$ disclosed binge drinking. Of the 418 patients $(84.8 \%)$ who responded, $73(17.5 \%)$ admitted recreational drug use. The most common method of use disclosed was smoking (71.2\%), 
followed by snorting (49.3\%) and pills (30.1\%). (31 reported more than 1 method.)

Discussion/conclusion Over half of patients attending our clinic warranted further assessment or brief intervention regarding their alcohol use. Recreational drug use and smoking was higher than that of the general population. Further staff training and developing links with local support services will improve the holistic management of our patients.

\section{P133 INTER-SPECIALITY WORKING TO PROVIDE COMPETENCIES IN GENITAL DERMATOLOGY FOR GUM TRAINEES}

Helen Colver*, Karen Harman. Leicester Royal Infirmary, Leicester, Leicestershire, UK

\subsection{6/sextrans-2016-052718.187}

Background The Health and Social Care Act (2012) led to decommissioning of genital dermatology services in our sexual health clinic, creating a training deficiency in this aspect of the GUM curriculum.

Objective To develop a service for patients with vulval pathology whilst also providing competencies in genital dermatology for GUM trainees.

Methods Training concerns were discussed with the local Health Education England board. A dermatology consultant with considerable experience in vulval disorders agreed to supervise a weekly vulval clinic, held within the dermatology department, to which GUM trainees would be seconded. Women were seen by a GUM trainee under the supervision of the dermatology consultant. Details of patient outcomes were prospectively recorded.

Results Over 10 months 84 women were seen in a total of 165 visits. The patients had a median age of 57 (range 19-94) years. $34(40.5 \%)$ were follow-up dermatology patients. Of the 50 remaining patients, 10 (20\%) were referred from other dermatology consultants, 3 (6\%) from gynaecology, 8 (16\%) from genitourinary medicine, and 29 (58\%) from general practice. Diagnoses are tabulated below.

\begin{tabular}{ll} 
Abstract P133 Table 1 & Genital dermatology \\
\hline Diagnosis & $\begin{array}{l}\text { Number of } \\
\text { patients }\end{array}$ \\
\hline Lichen sclerosus & 30 \\
Lichen planus & 15 \\
Dermatitis & 15 \\
Vulvodynia & 5 \\
Atrophic vaginitis & 4 \\
Lichen sclerosus/lichen planus & 3 \\
Psoriasis & 2 \\
Tinea & 2 \\
Vulval melanoma & 1 \\
Vulval Crohn's disease & 1 \\
Other & 6 \\
\hline
\end{tabular}

Discussion Inter-speciality working has allowed GUM trainees to develop expertise in genital dermatology whilst the presence of a GUM doctor facilitates exploration of psychosexual issues in these patients. We recommend that other centres consider this model for training and service provision.

\section{P134 MAINTAINING CONFIDENTIALITY IN SEXUAL HEALTH CLINICS; A LOCAL AND NATIONAL SERVICE EVALUATION}

${ }^{1}$ Rebecca Duffield, ${ }^{2}$ Emily Clarke, ${ }^{1}$ Mickaela Poree, ${ }^{2}$ Tony Lamb, ${ }^{3}$ Alan Tang, ${ }^{2}$ Elizabeth Foley, ${ }^{1}$ Raj Patel*. 'University of Southampton, Southampton, UK; ${ }^{2}$ GenitoUrinary Medicine Department, Royal South Hants Hospital, Southampton, UK; ${ }^{3} B A S H H$, Macclesfield, UK

\subsection{6/sextrans-2016-052718.188}

Background/introduction The need for confidentiality is of particular importance in sexual health clinics, as patients are sometimes reluctant to give personal contact information due to fears of disclosure to other parties. This can cause difficulties for clinicians when trying to issues results or advise patients of the need to attend for follow up.

Aim(s)/objectives To review the proportion of patients with Chlamydia Trachomatis who had their confidentiality/permissions (CP) breached in order to issue results, or who never received their results. To review UK wide policy in sexual health clinics on these issues.

Methods The EPRs of those attending a large provincial Sexual Health Department with a new diagnosis of Chlamydia Trachomatis between July 2014 and June 2015 were reviewed. A nationwide policy survey regarding breaches in CP in order to provide patients with results was disseminated to Lead Clinicians.

Results The records of 605 patients were reviewed. 4\% had their CP breached, of whom 18 (69\%) required follow up only, and $31 \%$ for the issue of positive results post treatment. $5 \%$ did not receive their results. $62(25 \%)$ of sexual health clinics returned surveys, of whom $16(26 \%)$ had a policy for issuing results when breaches were required.

Discussion/conclusion Breaching CP in order to issue results or ask patients to attend for follow up, or failing to give results, was common, affecting nearly 1 in 10 patients. The survey showed that a minority of UK clinics have formal policies addressing this issue. A BASHH national guideline would be helpful.

\section{P135 DO HIV SERVICES MEET THE NEEDS OF ADULTS DIAGNOSED WITH HIV AT AN OLDER AGE? A UK BASED, MULTI-CENTRE QUALITATIVE STUDY}

Sadie Bell*, Fabiola Martin, Joy Adamson, Tim Doran. University of York, York, UK

\subsection{6/sextrans-2016-052718.189}

Background/introduction As the number of new HIV diagnoses in adults aged $\geq 50$ years is increasing, the effectiveness of HIV services in meeting the needs of this group warrants exploration. Aim(s)/objectives Exploring HIV service provision for adults diagnosed with HIV at age $\geq 50$ years, from the perspectives of service users and healthcare professionals (HCP).

Methods Qualitative interviews with nine adults (age range 5067 years) diagnosed with $\mathrm{HIV}$ at age $\geq 50$ years and 12 sexual health/HIV HCP.

Results Service users reported a generally outstanding level of care delivery, and considered themselves to have a greater control of their health following diagnosis, primarily due to an increased level of support and general health monitoring (e.g. frequent blood pressure checks, blood tests, and regular followups). Some service users believed their life-expectancy may have improved after diagnosis. Perceived advantages were identified 